\title{
When a computer speaks institutional talk: Exploring challenges and potentials of virtual assistants in face-to-face advisory services
}

\author{
Mateusz Dolata \\ University of Zurich \\ dolata@ifi.uzh.ch
}

\author{
Mehmet Kilic \\ University of Zurich \\ kilic@ifi.uzh.ch
}

\author{
Gerhard Schwabe \\ University of Zurich \\ schwabe@ifi.uzh.ch
}

\begin{abstract}
Advisory services are a highly sensitive form of collaboration: they rely on a clear distribution of roles between human participants who act according to an implicit set of practices and scripts. As such, they do not offer a specific role to a virtual assistant. At the same time, the technological improvements make the promise that institutional settings may be soon complemented with technology that allows for asking questions using natural speech, understands the context, and provides answers based on online processing of data. This article explores challenges and potentials of virtual assistants in advisory services while analyzing data from interviews and a workshop with clients and advisors from financial advisory services. It links the insights from the field with the institutional talk perspective. The findings unveil, that the concerns and hopes of potential users relate to their position and an implicit understanding of what an advisory service is about. This calls for careful and attentive design approach towards virtual assistants in advisory services.
\end{abstract}

\section{Introduction}

A whole generation of research on face-to-face advisory services concludes that the presence of IT during encounter interaction shall be at minimum. Enforced or exhaustive usage of a computer may corrupt conversations [1], [2], hinder relationship building [3], and require longer and more intensive tuning in [4]. However, automated processing and documentation bears chance to reduce the pre- and post-processing overhead for the advisors [5], and enhance the transparency and persuasiveness [6]-[8]. Consequently, researchers made significant effort to hide the computer and to integrate the automated processing as much as much as possible with existing practices [9], [10].

Accordingly, the few successful systems [9] preserve the conventional character of advisory services as instances of institutional talk. This may cause wider adoption of IT but limits the opportunities for innovation. According to this concept, IT in service encounters remains a passive tool and advisor is the one who operates it. A computer resembles and replaces brochures or paper documents. This vision makes too little space for novel features: IT's potential to process complex information in seconds remains unused.

The recent development and diffusion of voicebased assistants and AI offers an alternative vision. Instead of reducing IT to advisor's tool, we envision an AI-based system able to interact with the advisors and advisees. For instance, it could generate recommendations on its own and communicate them to the participants. The fast progress concerning virtual assistants is likely to soon make companies and research institutions experiment with them in service encounters. This manuscript explores the potentials of this vision.

This manuscript asks the following question: What do advisors and advisees expect from an virtual assistant in an advisory service? The study uses 24 interviews and a workshop on financial advisory encounters at a bank to answer this question. The results show that virtual assistants bear potential to improve advisory services. However, it points to differences concerning how potential bank customers and how bank advisors see the identity of a virtual assistant in such encounters. The manuscript unveils controversies to be addressed before virtual assistants can enter the stage.

The collected insights point to a range of factors that may play a role for appropriation of virtual assistants in such institutional talk instances as face-to-face advisory services. This contribution adds to the previous knowledge on the design of advisory service support systems and to the emerging discourse on computer as teammates, while extending it to the service area. Designers can benefit from better understanding of problematic choices and how those relate to the context of interaction. Service scientists learn about service characteristics that seem most important to advisees and advisors. Finally, researchers approaching the topic of virtual assistants can learn about potentials existing in the area of institutional talk. Overall, practitioners and academia can benefit from the identified tendencies. 


\section{Related Work}

\subsection{Interaction in Advisory Services}

Advisory services are instances of institutional talk. They embrace a conversation between two actors following their organizational identities. The advisor tends to dominate in verbal and material interaction. She also controls the IT and access to the material [10]. Both, the advisor and the advisee behave according to generic scripts that characterize the adequate and appropriate interaction [10], [11]. This affects the turn taking (Who is allowed to speak when? Who distributes the right to talk?), overall structural and sequential organization (What parts does the interaction consists of? What utterances form acceptable reactions to what other statements?), lexical choice (What words do the participants use? How do make lexical choices?), and the expected differences between participants (Who knows more about what topic?) [12]. Accordingly, advisory services rely implicit rules and roles.

Financial advisory encounters are instances of institutional talk: they involve advisor representing the bank and the client acting towards his own goals; normally, the bank advisor controls the right to distribute turns, acts as host, and drives the interaction [10], [11]. The interaction sequence is characterized, to large extent, by question-answer adjacency pairs [13] and the literature argues for existence of specific modes or phases which are characterized as information collection, information provision and recommendation oriented at reduction of knowledge differences between the interlocutors [14], [15]. Overall, financial advisory services are well specified type of interaction, in which the advisor and the advisee both have their obligations and expectations, which originate from the shared scripts of this encounter type. However, it remains unclear, how a virtual assistant should be designed to dovetail with the expectations people have of an advisory service and how to blend in.

Recent studies approach the topic of material organization of advisory services. They identify ways in which the above mentioned roles reflect in usage of materials and documents [10], [16]. The advisor's dominance and control in verbal space correlates with her dominance over the space and access to material and tools - she is the one to structure and order the interaction space [10]. The documents she uses help structuring and segmenting the encounter [10], [16]. Overall, the advisor controls the access to the available tools and decides on their usage in the encounter. Impression management has been identified as a rationale for this strong dominance concerning the material and tools: advisors, even though sometimes implicitly, want to offer an experience to the advisee, which causes him to consider the advisor and the bank as orderly, trustworthy and transparent [10]. Additionally, documents and tools often carry specific meaning which goes beyond their content or form: they stand for abstract concepts and thus enable embodied interaction with otherwise virtual things [10]. Virtual assistants using solely voice-based user interface are likely to interfere with the existing configuration: Are they a material, physical resource? Are they a tool the advisor has control of or are they, maybe, a shared resource?

\subsection{IT in Advisory Services}

Previous research on IT support in advisory services approached those and similar questions with regard to more conventional technologies. A whole research program investigated design and usage of touch-based interfaces for advisory services [3], [5]-[7], [9], [17]. Particularly for the use during the financial advisory services, the proposed designs evolved from systems based on touch-tables filling the whole interaction space [3], [6], over table-tops which took less space [1], [17] and tablets which could be used as private or shared devices [13] up to approaches using augmented reality and enabling to hide the computer altogether and return to paper-based modes of interaction [18]. Overall, many approaches were considered for advisory services.

The research has shown that a dominating presence of technology may have negative effects concerning the relationship building [3], unintendedly enforces a process or a set of actions simply by visualizing it thus generating a feeling of coercion [6], [17], changes the sequential character of the encounter by extending the tuning-in phase [4], or simply generates situations in which the advisee is unsure whether the advisor is receptive to his verbal contributions or not while working with IT [1]. Those unwanted effects were shown to distract the character of the encounter, destroyed the natural flow of the conversation (while, e.g., creating phases of formfilling-like interaction [17]) and hampered the impression management and rapport building [3], [4]. Overall, the previous research again illustrates the importance of material and embodied interaction for smooth institutional talk experience in advisory services.

However, the solutions proposed in the past offered improvements as well. They were shown to enhance the transparency of the financial encounters [6], lead to more intensive exchange of information and better knowledge transfer [13], [19], and enhanced the overall satisfaction with pragmatic and hedonic elements of the service [18]. Beyond the financial domain, the tools helped establishing more effective advisory practices leading to empowered advisors [20], enhanced persuasion [7], [8], more joyful interaction between the interlocutors [21] and better in-process documentation [5]. Virtual assistants have potential to extend this, while 
giving the computer access to the verbal communication between the advisor and the advisee.

Many negative effects reported in the previous studies could be attributed to unintended changes in the implicit scripts driving the service encounters [1], [17]. This points towards possible issues to occur when virtual assistants will enter the stage. While the previous systems were all designed as passive and deterministic tools. Those systems were active during use and their actions were largely predictable [5], [9], the use of virtual assistants adds to the complexity. They are agents and not tools - they could activate themselves without explicit request but based on the inferred state of the conversation and they produce output based on probability. Consequently, the design of virtual assistant advisory services requires much care and awareness of the highly sensitive matter.

However, virtual assistants offer potential improvements. Previous systems needed either an explicit input through touch, keyboard or analyzed the notes advisors created on paper or on tablet [1], [22]. The captured verbal conduct could enhance documentation as well as offer new interaction paradigms with the system. Furthermore, through access to data and ability to process it automatically, a virtual assistant can dynamically extend the knowledge base of information available in the conversation. Thereto it can integrate sources of knowledge, advisor does not have access to or it would be timecostly to consult them during the service. Finally, through voice production, a virtual assistant could offer a new way of presenting information, unavailable before. A virtual assistant as envisioned here can be compared to the systems available on the market like Apple's Siri, Google Assistant or Amazon Echo, with the essential difference that it is suited to be used in conversations (rather than single user scenario), which it listens to, transcribes and uses as a source of inference, and with access to specific bank's data apart from openly accessible sources.

\subsection{Virtual Assistants in Collaboration}

The idea of including virtual assistants in collaboration has been discussed for years [23]. However, recent improvements in technology as well as development and innovation offensive of large companies like Microsoft [24] has fueled the discourse again [25]. The research discusses opportunities that follow from positioning computers as teammates rather than tools [23], [25] and claim large potential for the organizations and for the users. This trend sets on a hybrid solution as opposite to the discourse on replacing humans by machines and references to such developments as Industry 4.0 or co-creation in services [25]. This is in line with earlier research claiming that humans attach human qualities to pieces of technology around them [26] and can involve a switch of paradigms from Heideggerian postilion which postulates that technology dissolves in human practices and becomes equipment defined through its usage rather than through its qualities [27], [28].

Simultaneously, research analyzing interaction with existing virtual assistants explicate how a multi-party collaborative behavior emerges when Siri or Alexa is used in a group setting [29], [30]. Actions involving virtual assistants are accountable to other humans such that they involve in the interaction through bodily and verbal reactions [30], thus generating a multi-party interaction - a social conduct, being together. This is so even though the off-the-shelf virtual assistants are set primarily for a dialogue situation with a single human. Research in human-robot interaction addresses low-level aspects of coordination in multiparty conversations [31], [32] as well as high-level determinants of satisfying communication between humans and robots, such as rapport-building or empathy [33]-[36]. In particular, several studies make efforts to create virtual agents for service tasks able to engage in multimodal (e.g., voice, gaze, mimics) communication with a client that transfers friendliness, rapport or expertise [35], [36]. However, the literature still lacks an understanding of how virtual agents can be integrated into service encounters lead by a human, as opposite to the ones where the robot takes on the role of service provider. Furthermore, while the studies identify low-level patterns of interaction typical for services and implement them, they do not explicitly address the obligations and expectations that follow from the scripts typical for institutional talk.

\section{Method}

To explore the challenges and potentials virtual assistant in institutional settings, this research employs a qualitative paradigm. Given the focus on the financial advisory services, it is designed to collect opinions from individuals who experienced financial advisory encounter. Furthermore, given the highly creative and visionary topic, it employs several techniques to put the subjects into position of generating new ideas rather than reporting. And, of course, it aims at collecting input from both sides of the financial advisory service, i.e., from advisors and from the advisees.

In particular, to collect input from advisees we interview 24 individuals who participated in advisory service simulation. The participants were acquired through an invitation on a university announcement page used widely to attract participants for scientific studies. The participants were on average 31 years old (min. 21, max. 62) and came from a variety of professional backgrounds (including nurses, students, controlling-employees, quality management officer, etc.). Ten subjects 
were female, 14 - male. All participants attended to two advisory services, one supported with a prototypical tablet-based advisory tool and one without any technological support. The order was permutated. The system was designed in accordance with the design principles available in the literature [10], [17] - it did not implement a virtual assistant. Instead, it offered screens for visualizing and manipulating information advisor provides to the advisee. Based on this experience, the subjects could identify differences between services with and without IT and were made sensitive to the changes in the interpersonal dynamics.

The advisory services were conducted by real advisors from a local Swiss bank - each test advisee received both services from the same advisor. After attending to the service encounters, the test advisees were invited to an interview where they reflected on the differences they observed. To put them into the position to think creatively about potentials and challenges of virtual assistant, they were confronted with ideas on how the presented tool could be extended with qualities of a virtual assistant (answering knowledge questions based on the context, providing a written report upon the completion of the service, listen to the conversation and enter when appropriate). Additionally, a researcher presented a small carving on how the virtual assistant could look like. The advisees were asked a number of questions concerning their vision of an advisory service involving use of such an assistant. In particular (1) they should identify situations in the services they attended, where such assistant could generate an additional value, (2) they should describe how the interaction with the virtual assistant would look like in those situations, and (3) they should explain their motives for specific design suggestions. Additionally, they were asked some follow up questions to specify the ideas, to attach a label or name to the envisioned virtual assistant or encouraged to play through a simple interaction together with the interviewer. Overall, the client interviewees were put in a position to relate to a recent experience of financial services, as well as induced to switch from a reflective to a creative and visionary mode. This resulted in 24 recorded interviews. Subsequently, the interviews were transcribed and coded to identify repetitive ideas and dominating fears or concerns. The coding followed the bottom-up manner and focused on ideas (to identify those which appear across the data set), general perceptions and experiences regarding virtual assistants (to understand subject's background), and references to the scripts, obligations and expectations towards an advisory service supported with a virtual assistant (to understand how they may change).

To collect advisors' opinions and envisioned interaction, we launched a workshop with 8 participants including two advisors, two advisory service experts, and four university members. The workshop format should establish a creative atmosphere for the advisors and encourage them to freely talk about potential visions and problems. The workshop included a short introduction on the currently available virtual assistants including a demo of Alexa Echo to provide a common starting point and make the participants aware of potential interaction styles. The main part of the workshop consisted of a design session, where two teams (each team had at least one advisor and one expert) were asked to design an advisory session in which a virtual assistant is used. They were informed that later on they will role play the designed session, such that the advisor will take on her professional role of the advisor and a university member will act as a client. Given the fact that Alexa Echo does not possess skills relevant for an investment advice (e.g., calculating potential risks), another team member was instructed to act as the virtual assistant according to the scenario prepared by the team. The same members were also instructed to mimic usability problems of the Alexa which have not been foreseen in the scenario. This shall guarantee for an experience, which would resemble an interaction with a probabilistic system. After the simulation role play, the participants discussed their experiences and design decision implemented in the simulated advisory encounter. The whole workshop was audio recorded to allow for the analysis of intermediate (e.g., made during design phase) as well as final statements. The simulations were video recorded to allow for an analysis of interaction dynamics within the simulations. The material was analyzed according to the multimodal analysis practice [37]. Overall, the collected material produced a set of relevant statements from the advisees and from the advisors.

\section{Results}

\subsection{Client interviews}

The client interviewees offer a range of interesting thoughts on how an assistant could support a conversation between the advisor and the advisee in a service encounter. In particular, they identify two main attributes of the assistant: the ability to make judgement based on large data sets as well as the ability to provide additional information and quick calculations. A client puts it like that: ,It could make a prediction [for the property price]. That would be exciting and would give me a second opinion, which could calm me down. Especially if it were positive, if it were in the green range of the expected price. [...] That would be an added benefit. [...] The statistics could support my confidence and take away the uncertainty" (K08). The client claims some sorts of external information could be even more important than information coming from the advisor: "I 
would trust it more! It's like a doctor who's seen 10,000 $x$-rays, but the computer has already compared 14 million pictures, then I personally have the better feeling with the diagnosis of the computer" (K08). Additionally, the advisees point to some advantages that would come with transcription of meetings for their personal record. An advisee says: "I would read the transcript, yes! You sometimes notice later on that you forgot something or are even unsure if you asked a question. This would help"(K17). Overall, the interviews identify potentials within the range considered typical "computer" tasks: searching data, calculating or documenting.

If it comes to the design of interaction within a service encounter, the client interviewees seem to value the clear interaction with the advisor over the interaction with the virtual assistant. „I may be a bit old-fashioned, but I'd still prefer it to have the main part of the conversation with the advisor. I would see [the assistant] more as an additional technical feature. [...] For example, if you could set some parameters and then say: 'Give me the 20 mixes that make sense in this situation' and I could discuss them with the consultant" (K09). In particular, the interviewees do not see much need or space for verbal contribution from the assistant: ,The additional information could [...] be delivered to the tablet. Then the advisor could take the role of the mediator" (K08). The interviewees fear for the quality of interaction with the advisor if there was a virtual assistant who takes part in the conversation: "I would see it more as a text message than something spoken. That'd be a little weird. It's almost getting a little too human for me. [...] [When visualized] it won't disturb the conversation" (K14). Most client interviewees see the virtual assistant in a passive role and prefer to keep the social structure untouched. However, some question the concept of advisory service as an interaction between humans altogether: ,, Then the question immediately arises why we even needs advisors. What is the nature of advisor's job? This question arises for me anyway. Why can't I do this alone on the PC if I have access to the tool and if I can still ask questions if something is not clear in the tool. [...] Then I would not have to come to the bank office. That would suit me well" (K07). Still, the clients tend to prefer the advisory services in a dyadic configuration with the strong position of the advisor.

The interviewees point to specific potential sources of disturbance and insecurity being (a) undefined addressee of a statement: "It would be a little confusing to find out whether to ask the advisor or the digital assistant" (K15) and (b) not predictable conversational behavior of an assistant: "If the robot suddenly says something, it is disturbing. When a person like you gets involved [...] then I see that you have something to say. This is not the case with a computer, so it is usually disturbing. He suddenly speaks, and you are not prepared at all" (K08). Some interviewees propose ways to prevent the confusion by adding additional structures with clear division of roles: "In the first part between the advisor and the client, the assistant would be listening, taking notes and thinking about what kind of questions could be asked. Then the client should first ask questions and the consultant should say what he thinks and then the assistant could come into play in the second phase" (K17). Overall, the interviewed clients put emphasis on clear, stable and predictable, if not even scripted structure of an advisory encounter.

Table 1. Summary of differences between advisors' and clients' opinions according to the identified dimensions characterizing the virtual assistant

\begin{tabular}{|l|l|l|}
\hline $\begin{array}{l}\text { Virtual assistant's } \\
\text { characteristics }\end{array}$ & \multicolumn{1}{l|}{$\begin{array}{l}\text { Clients' view (in- } \\
\text { terviews) }\end{array}$} & \multicolumn{1}{|c|}{$\begin{array}{l}\text { Advisors' view } \\
\text { (workshop) }\end{array}$} \\
\hline Physical presence & $\begin{array}{l}\text { Integrated in exist- } \\
\text { ing tools, hidden }\end{array}$ & Visible, animated \\
\hline Anthropomorphism & $\begin{array}{l}\text { Different from hu- } \\
\text { man }\end{array}$ & $\begin{array}{l}\text { Similar to human, } \\
\text { has a name }\end{array}$ \\
\hline Speech production & $\begin{array}{l}\text { Not necessary, vis- } \\
\text { ualizing suffices }\end{array}$ & $\begin{array}{l}\text { Yes, when fits the } \\
\text { amount and char- } \\
\text { acter of data }\end{array}$ \\
\hline $\begin{array}{l}\text { Initiation of interac- } \\
\text { tion by the client }\end{array}$ & $\begin{array}{l}\text { No, interaction } \\
\text { through advisor }\end{array}$ & $\begin{array}{l}\text { Yes, after intro- } \\
\text { duction at the be- } \\
\text { ginning }\end{array}$ \\
\hline $\begin{array}{l}\text { Introduction at the } \\
\text { beginning }\end{array}$ & Yes, by advisor & $\begin{array}{l}\text { Yes, by the system } \\
\text { itself (after advi- } \\
\text { sors' request) }\end{array}$ \\
\hline
\end{tabular}

\subsection{Simulation workshop}

The advisor's opinions collected in the workshop confirm the potentials pointed out by the clients. An advisor, already before the design and simulation parts of the workshop explains the value of access to external data: "We always prepare and take certain documents with us, but the conversations create new needs, new ideas. And if you can then query via assistant and can also visualize directly, I think the customer can get much more out of it and the advisor can offer also much more individualized advice with a very little time. Because you have everything available" (A1). Confronted with the question if the external information could generate dissonance on the client's side or even compromise on the advisor's advice, she responds: "Not if you are a good advisor. I think that's a coexistence. And if you can use all these tools properly, you will increase the output of your work and you will become more efficient. And in the end, the customer benefits, he is happier. And then really is a win-win situation [...] Yes, that makes you a translator. You have to explain to the customer in his words what the assistant generated as output. And that is the competence of the consultant" (A1). The other advisor extends this by saying: "And you can really underpin your words and explain 'Look, I'll tell you that now, that's because here and here..."” (A2). This comment 
points to the general tone of the statements: it is important for the advisor to speak the last word. However, the advisors also see potential for documentation and would even see direct potential for using it in the conversation: "It could even help regarding legal and compliance when it's all recorded. You may be able to review the conversation with the customer: 'We have discussed all this and that' and then create an automatic summary that can be printed out" (A2). Overall, the advisors see potentials and use scenarios compatible with those illustrated by the clients in the interviews. However, the advisors also stress the fact, that this external information cannot be left without commentary from them and that it should be use as a chance to involve the client in a further discussion.

When designing the role play, the advisors and experts (distributed across teams) discussed the way for interacting with the virtual assistant and for establishing its presence during the advisory service. An advisor explains how he would proceed about opening the encounter: "Before I go into a room, I would certainly make the customer aware. 'Is that ok for you? We have a new technology. Can we do that like that?'. I would explain briefly the situation and then maybe offer a short test phase. 'Look, this is our assistant. Ask him a question on whatever you like' [...] And then he would answer. And then I would explain 'Look, if I hit him on the head, then he's out. Then he takes no notes, does not speak. Then we are really among us. Is that ok for you?' [...] And then [...] I say to the assistant 'Today, Mister Whatever is here, please say hello to him' and the advisor would introduce himself and the bank" (A1). If it comes to the presence of the assistant in the room, the advisors favor a separate and clearly visible character distinct from themselves with a space for presentation of information: "A hologram would be great! [...] You have to see the hologram when it speaks, but slides and factsheets, etc. must still be visible somewhere else. Of course, that would be cool to see it directly on the table. [...] A hybrid solution" (A2). Furthermore, the way of involving the assistant in the ongoing conversation was discussed. Both teams preferred the situation in which a human starts the interaction "And then I go back to the assistant 'So the customer is well insured, what do you mean?'. I pick up the confirmation from the assistant. And then I can tell the customer: 'Okay, so you are very well insured'. [...] I mean, pretty easy and straightforward: 'Do you agree, Hypi?',' (A1). Hypi was the name, this advisor assigned to the virtual assistant. Overall, the advisors proposed a pretty dynamic, speech and visualization-based interaction with the assistant. During the role-play the advisors behaved accordingly with specific micro-behaviors: when addressing the assistant (whose voice and output was, as explained, mimicked by a university member), they were turning their heads up, to the side, or to the specimen standing for the assistant in the situation. Additionally, even those in planning phase, they often cited requests to the assistant, by putting its name at the end of the sentence, during the actual simulation, they always put the assistant name first. Which resulted in "Hypi, do you agree that Mister Whatever is well insured?" or similar requests. Overall, the advisors and also the university members enacting the advisees conducted the role play with a mixture of improvised and predefined sequences.

The information collected after the simulation was throughout positive and confirmed or even strengthened the statements collected before. An advisor expresses his positive attitude the following way: "I was actually very surprised about how fluent the conversation went. Even though Hypi was making problems now and then, it was still more fluent and enjoyable than a standard conversation, when I would need to look up the information online using the computer. (...) I was relaxed and could concentrate more on the client. I liked it" (A1). Another advisor was confirming the feeling and even was more convinced about the necessity to keep it running throughout the advisory session: "I think it's important it listens continuously and knows the context. There could be small switch somewhere to disable this when the client explicitly wishes to, but otherwise I wouldn't even suggest it to them" (A2). However, they also acknowledge there is another side to that: "But then again, I can well imagine [...] to what extent such a language assistant can be a problem again. Because financial matters have always been a problematic thing: People do not like to talk about it publicly. And then there is that device that listens to it" (A2). They also noticed limitations for themselves: "You need to improvise, especially when you do not know if it heard your request or not. It needs to be clear. But sometimes such a break can be useful-it's anytime shorter than when you need to look up things online with a computer" (A1). Overall, the simulation itself offered a confirmatory evidence to the statements advisors made ahead of it. However, it also made clear, that not every contribution from the assistant is acceptable to the advisors - on a proposition that the assistant could introduce relevant questions to be asked or suggest topics to be discussed an advisor argues clearly against it: "I wouldn't like it to say things like that. I should control it. It's my competence to know when to ask for additional information or make an offer. This could be on the tablet or the table with some markings, invisible to the client, but without interrupts" (A2). The argumentation often refers to how the situation better looks to the client: this refers to the fluency of interaction but also to what is visible and how. Table 1 summarizes the opinions collected in the interviews and during the workshop. It points to a difference between the clients, who prefer a hidden or disappearing assistant 
integrated into the conventional situation, and advisors, who argue for a visible and more active (but not proactive) assistant.

\section{Discussion}

The results make clear that introducing a virtual assistant in the institutional talk poses risky challenges. The clients see potentials of introducing an additional assistant in the setting: a second independent opinion or access to wider information sources. However, having a third potentially active entity in the setting may cause confusion. The interview participants provide visions, in which the virtual assistant is hidden, can be accessed only by the advisor or can enter the stage only after a discussion between the human actors. Few of them propose a path in which the assistant could altogether replace the advisor. What unites the statements is the reference to the script of the advisory setting and the notion that this script does not foresee a clear role for another, third party. Consequently, the clients tend to push the assistant into the responsibility of the advisor: they propose various interfaces on how the advisor could interact with the assistant and see her in the responsibility of moderating or mediating. Instead of envisioning a team of three partners with direct interfaces between each other, they propose a dyadic structure: client and advisor, where the latter may consist of human and virtual assistant or just any of them.

A dyadic configuration roots deeply in the character of institutional talk. Actors in an institutional talk act on behalf of their institutional identities and the script of an advisory encounter foresees primarily two identities: an independent client and an advisor who represents the service provider (in case of financial services, a bank) [4]. In that sense, the responses from the clients are expressions of a try to attach an institutional identity to the virtual assistant. While some see the potential of providing a data-driven, independent third party, others settle on the known identities and attach the virtual assistant to the advisor. In fact, even those interviewees who see a potential for a third role, relativize it: they say, it would be probably the bank who provides the data and, thus, can control the assistant. Overall, the clients tend to implicitly or explicitly position the assistant as sharing the institutional identity with the advisor.

Consequently, to allow for an equal and team-like interaction between the advisor, the client and the virtual assistant, the frames of institutional talk need redefinition. In particular, the new configuration requires an independent third source of an institutional identity. In simple words, whereas the client speaks for himself and the advisor for the bank, there needs to be a third authority behind the virtual assistant. This might be the provider of a knowledge base consisting of a large number of cases or of a separate prediction. A bunch of such independent authorities has been already present in financial advisory encounters. The advisors often mention the market supervisory authority as a source of rules that govern the process and criteria for mortgage or classification of investment products. They also refer to property pricing models from independent organizations, they need to consult to assess the actual value of a house. Furthermore, in investment advice, they refer to independent comparison of product performance. The references may have only verbal character, but often they materialize: the advisor may use a printout which clearly shows it is not issued by the bank or may point to a citation in the bank's own brochures. In investment advice, they sometimes consult known online broking websites for data about specific stocks or derivates on the computer. All those identities already exist in financial advisory encounters and in other institutional settings. Accordingly: a virtual assistant could easily borrow identity from an independent organization and thus make it easier for the clients to accept it as a partner.

Interestingly, the workshop with the advisors shows that advisors are not afraid of dealing with external sources of information in the advisory setting. Advisors' statements during the simulation workshop point into a different direction. They reason while referring to their daily practice of using external sources in advisory services and to how it may impact the impression it makes on the client. In particular, they see that a virtual assistant opens possibility to integrate the use of external sources into the ongoing interaction, without the necessity to interrupt the conversation to search for the information online. Caring about this impression of an organized, well prepared service, with little necessity to improvise has been previously described in context of the material performance of financial advisors [10]. We argue, that the same rationale gets expressed here as well: an advisor who uses a computer to search online for the necessary information does not appear to the client as responsive enough to maintain the conversation [1], therefore both participants focus on the improvised search over a longer time than if the question is forwarded to an assistant. Simply put, redirecting a surprising question to a virtual assistant reduces the improvisation character and provides more time for relationship building with the client [3]. This allows the advisor to turn the focus away from the technology.

Still, the advisors feel responsible for introducing the assistant to the client. Statements collected during the workshop make clear, that the advisors care much about how the assistant presents itself to the client. The requests for an actual, extensive greeting correlates with the wish of the advisors to provide the virtual assistant with a visible and, if possible, animated form (hologram, emoticon). This goes in exactly the opposite direction to 
what most client interviewees were proposing: advisors want the assistant to be clearly visible, to take space and time during the interaction. The advisor's argumentation goes towards more natural interaction and, in fact, the behavior of the participants is in line with this. In the simulations, they were turning their bodies or heads towards the physical representation of an assistant. We argue, that those propositions go in line with the advisor's interest to maintain the right impression in the advisee [10]: clear differentiation between the advisor and the assistant can help the advisor make her own standpoint clear and diverse from what the assistant suggests.

While the advantages concerning impression management and conversation fluency were discussed most, advisors identified a range of further application scenarios. In particular, process suggestions or possibilities for cross-selling could improve the service, however, should be hidden from the client. Advisors' argumentation approaches the competence and impression again: while showing missing knowledge of a stock rating is acceptable, forgetting about a relevant question seems problematic, such that the advisors would not like the advisees to notice it. Translating knowledge-related content seems acceptable to the advisor, while translating (and thus explicating) elements of the process goes beyond their understanding of the role of a translator. The advisors prefer to keep control over the situation in this regard, alike they kept control of turn taking during the simulations. This relates clearly to their institutional position in this setting - bank representative and, at the same time, the host and moderator [10], [11]. Overall, there seems to be areas where the assistant can have its own voice and make contributions on its own, but there are taboo topics, which it should not address in a loud manner in front of the client. Those include process suggestions and should be made as invisible as possible, but accessible to the advisor when needed.

The discussion of the observations makes clear, that a designer approaching the topic of virtual assistants in institutional talk needs to consider several essential features concerning the social position of the assistant. Table 1 points out how different the opinions are. It seems that client prefer less social presence of a virtual assistant while the advisors see more potential and thus accept its stronger presence. Whereas previous research on the perception of technology as social actors postulated that humans attach human and social characteristics, such as intentions, to technology [26], this research makes clear that they may wish for technology design that suggests the human character in a more or less explicit manner. This contradicts the previous research on supporting advisory services, which claimed that hiding technology is the ultimate direction of development to make the conversation more fluent [1], [4] and to establish space for rapport building [2], [3]. As the opinions from the workshop suggest, turning the assistant into a third actor, may actually generate the same effect. However, as interviews point out, there is a large portion of reservation towards virtual assistants attached to the script of institutional talk. Consequently, embedding virtual agents into situations like this needs further research and guidance.

The results and their interpretation lead to a set of suggestions that may help with embedding virtual assistants in the institutional talk settings:

(1) The virtual assistant requires its own institutional identity different from the ones attached to the human participants. In order to offer a consistent experience of an institutional setting, the virtual assistant requires an independent and clear identity it represents. Sharing identity with any side moves it to the position of a human participant's tool rather than a team member. As a tool or the Heideggerian equipment [27] it is expected to disappear in the situation rather than making contributions on its own [28]. But the switch to virtual assistants may imply switch in the Heideggerian perspective on technology use as well: the dissolving in the situation may occur due to taking on human-like characteristics. In this case, the technology would become an element of social conduct rather than equipment. In particular, in financial encounters, the virtual assistant could represent the market supervisory authority, a service assessing the property value, or an independent investment specialist. Discussions of the assistant's physical form and presence require clarification of the identity.

(2) The virtual assistant should not make the dynamics of an institutional encounter explicit. The institutional talk relies on a set of implicit assumptions, conversational rules and processes. Knowing about them may help the virtual assistant process the information in the right manner. However, making the implicit practices and processes explicit has been already previously shown to disturb a natural interaction in advisory encounters [6], [17]. The same holds for virtual assistants. If a virtual assistant signalizes a cross-selling opportunity or a question to be asked, in fact, it offers a microform of process guidance. In financial advisory services, it disturbs the conversational flow in two ways: it takes the process competence away from the advisor (thus changing his institutional identity) and it does not leave space for the intuitive choices of participants. In the envisioned scenario, process guidance was accepted only in form of a semi-visible, content-free signal that unveils its content after request.

(3) The virtual assistant requires a physical representation that fits its identity. The institutional talk is often described in terms of its material character [10], [16], where documents and items represent complex but essential concepts, while also being tools for managing the interaction in terms of focus or turn taking. Introducing 
an invisible actor hampers making unambiguous physical reference. In the financial advisory encounter, the advisor should be able to make an explicit deictic reference especially when integrating information from the agent into her narrative or when making clear, who has the right to take the turn.

Overall, institutional talk encounters posit a specific challenge to the machine-as-teammates concept. The challenges go beyond the standard questions concerning the division of labor between a human and a machine based on their critical skills [23], [25] and cannot be reduced to the use of conversational agents or assistants in any multi-party conversation [29]. While coordinating multiparty conversation involving a robot is a prerequisite [31], [32], the current study explicates the turn-taking and rights-distribution issues of service encounters to be obeyed. Also, while it is essential to address empathy or friendliness between robots and users [33] [36], this study emphasizes, that this cannot interfere with rapport building between participants. In particular, the dynamics of institutional talk generates issues related to the identities attached to the participants and how they manage impression and impact the impression management practices of others. Addressing these challenges seems worthy given the potentials of virtual assistants: better and more comprehensive documentation from the conversation transcript rather than notes; more fluent conversation thanks to delegation of online search tasks; more time for rapport building and mutual understanding; easier compliance with regulatory demands concerning decision traceability.

\section{Limitations and conclusions}

The results and the derived insights do not come without limitations. This paper has, clearly, an exploratory character and there are steps left for follow up research projects. First, confronting the potential users with a system able to process conversations could produce more valid results. So far, the insights rely on the assumption that interviewees as well as the participants of the simulation workshop possess enough imagination to identify issues and potentials in hypothetical rather than real situations. Second, extending the analysis to interviews and workshops with further advisors from financial realm and beyond this could provide better explanation for their attitude and generate even more diverse standpoints. Third, consulting management and lawyers is necessary to identify organizational and juristic burdens for including virtual conversational assistants in the interaction with clients. Fourth, the internal validity of the analysis could be enhanced through involving more researchers and relying on the inter-subjective derivation of insights. The authors acknowledge the fact that the current article certainly makes several unusual claims following from its theoretical underpinning. Ultimately, the proposed design suggestions should be validated through design of a system and application in practice. However, and this is clearly the central limitation to the current study, we refer to technology which does not exist yet in the form envisioned here and it remains open, whether this technology can offer the necessary accuracy and features.

Overall, this article demonstrates chances and challenges regarding the introduction of virtual assistants into institutional setting at the example of financial advisory services. The provided guidance shall drive design efforts in related fields and point the involved researchers and practitioners to relevant factors beyond the issues of technical practicability and business viability. It extends the emerging discourse on machines-asteammates in IS and computer-supported cooperative work to the topic of institutional talk - the article applies knowledge of institutional talk to the concept of virtual assistants. This can inform further behavioral and design explorations, which will surely occur, given the demand and interest from the organizations. Additionally, this article extends the focus of institutional talk discourse beyond its traditional scope: it explicates how deeply the institutional talk resides in clients and how this framing drives perception of new technologies.

\section{References}

[1] M. Kilic, M. Dolata, and G. Schwabe, "How IT-Artifacts Disturb Advice Giving - Insights from Analyzing Implicit Communication," in Proc. Hawaii Intl. Conf. System Sciences, 2016, pp. 878-887.

[2] C. Pearce, M. Arnold, C. B. Phillips, S. Trumble, and K. Dwan, "The many faces of the computer: An analysis of clinical software in the primary care consultation," International Journal of Medical Informatics, vol. 81, no. 7, pp. 475-484, Jul. 2012.

[3] P. Heinrich, M. Kilic, F.-R. Aschoff, and G. Schwabe, "Enabling relationship building in tabletop-supported advisory settings," in Proc. Conf. Computer Supported Cooperative Work and Social Computing, 2014, pp. 171-183.

[4] M. Dolata and G. Schwabe, "Tuning in to More Interactivity - Learning from IT Support for Advisory Service Encounters," i-com: Journal of Interactive Media, vol. 16, no. 1, pp. 23-33, 2017.

[5] T. Giesbrecht, T. Comes, and G. Schwabe, "Back in Sight, Back in Mind: Picture-Centric Support for Mobile Counseling Sessions," in Proc. Conf. Computer Supported Cooperative Work, 2015.

[6] P. Nussbaumer, I. Matter, and G. Schwabe, "'Enforced' vs. 'Casual' Transparency - Findings from IT-Supported Financial Advisory Encounters," ACM Trans. Management Information Systems, vol. 3, no. 2, pp. 11:1-11:19, Jul. 2012. 
[7] T. Comes and G. Schwabe, "How to diminish advice discounting with mobile multimedia interventions," in Proc. European Conf. on Information Systems, 2016.

[8] M. Dolata, T. Comes, B. Schenk, and G. Schwabe, "Persuasive Practices: Learning from Home Security Advisory Services," in Proc. International Conference on Persuasive Technology, 2016, pp. 176-188.

[9] M. Dolata and G. Schwabe, "Don't be afraid! Persuasive Practices in the Wild," J. Computer Supported Cooperative Work (CSCW), 2018.

[10] M. Dolata and G. Schwabe, "Paper Practices in Institutional Talk: How Financial Advisors Impress their Clients," J. Comput Supported Coop Work (CSCW), pp. 769-805, Jun. 2017.

[11] J. Svennevig, "Institutional and conversational modes of talk in bureaucratic consultations," in Meetings at the crossroads. Oslo: Novus, 2001, pp. 106-135.

[12] J. Heritage and S. Clayman, "Dimensions of Institutional Talk," in Talk in Action, Chichester, West Sussex; Malden, Mass.: Wiley-Blackwell, 2010, pp. 34-50.

[13] M. Kilic, M. Dolata, and G. Schwabe, "Why do you ask all those questions? Supporting client profiling in financial service encounters," in Proc. Hawaii Intl. Conf. System Sciences, Waikoloa Beach, HI, USA, 2017.

[14] H. Jungermann, "Advice giving and taking," in Proc. Hawaii Intl. Conf. System Sciences, 1999, vol. Track1.

[15] A. Oehler and D. Kohlert, "Financial Advice Giving and Taking-Where are the Market's Self-healing Powers and a Functioning Legal Framework When We Need Them?," J Consum Policy, vol. 32, no. 2, pp. 91-116, Jun. 2009.

[16] K. Svinhufvud and S. Vehviläinen, "Papers, documents, and the opening of an academic supervision encounter," Text \& Talk, vol. 33, no. 1, pp. 139-166, 2013.

[17] M. Kilic, P. Heinrich, and G. Schwabe, "Coercing into Completeness in Financial Advisory Service Encounters," 2015, pp. 1324-1335.

[18] M. Dolata, D. Agotai, S. Schubiger, and G. Schwabe, "High-Touch, High-Quality Service Interaction: Human-Centered Financial Advisory Services with Tangible Pen \& Paper Interfaces," [under review], 2018.

[19] P. Heinrich, M. Kilic, and G. Schwabe, "Microworlds as the locus of consumer education in financial advisory services," in Proc. Intl. Conf. on Information Systems, 2014.

[20] T. Giesbrecht, B. Schenk, and G. Schwabe, "Learning with Facilitation Affordances: The Case of Citizens' Advice Services," in Proceedings of European Conference on Information Systems, 2014.

[21] J. Novak and S. Schmidt, "When Joy Matters: The Importance of Hedonic Stimulation in Collocated Collaboration with Large-Displays," in Human-Computer Interaction. Springer Berlin Heidelberg, 2009, pp. 618-629.

[22] S. Heyman and H. Artman, "Computer Support for Financial Advisors and Their Clients: Co-creating an Investment Plan," in Proc. Conf. Computer Supported
Cooperative Work and Social Computing, New York, NY, USA, 2015, pp. 1313-1323.

[23] C. Nass, B. J. Fogg, and Y. Moon, "Can computers be teammates?," International Journal of Human-Computer Studies, vol. 45, no. 6, pp. 669-678, Dec. 1996.

[24] C. Mills, "The 5 biggest announcements from Microsoft's Build event," BGR, 07-May-2018. .

[25] I. Seeber et al., "Machines as Teammates: A Collaboration Research Agenda," presented at the Hawaii Intl. Conf. System Sciences, 2018, p. 10.

[26] B. Reeves and C. Nass, The media equation: how people treat computers, television, and new media like real people and places, 1. paperback ed., [reprint.]. Stanford, Calif: CSLI Publ, 2003.

[27] M. Heidegger, Being and Time... Translated by John Macquarrie \& Edward Robinson. London, 1962.

[28] K. Riemer and R. Johnston, “Artifact or Equipment? Rethinking the Core of IS using Heidegger's ways of being," in Proc. Intl. Conf. Information Systems, 2011.

[29] M. Porcheron et al., "Talking with Conversational Agents in Collaborative Action," in Companion of the 2017 ACM Conference on Computer Supported Cooperative Work and Social Computing, New York, NY, USA, 2017, pp. 431-436.

[30] M. Porcheron, J. E. Fischer, S. Reeves, and S. Sharples, "Voice Interfaces in Everyday Life," in Proceedings of the 2018 CHI Conference on Human Factors in Computing Systems, New York, USA, 2018, pp. 640:1-640:12.

[31] Y. Matsusaka, S. Fujie, and T. Kobayashi, "Modeling of Conversational Strategy for the Robot Participating in the Group Conversation," p. 4, 2001.

[32] S. Satake, T. Kanda, D. F. Glas, M. Imai, H. Ishiguro, and N. Hagita, "How to Approach Humans?: Strategies for Social Robots to Initiate Interaction," in Proc. Intl. Conf. Human Robot Interaction, New York, NY, USA, 2009, pp. 109-116.

[33] J. Cassell et al., "Embodiment in Conversational Interfaces: Rea," in Proc. Conf. Human Factors in Computing Systems, New York, NY, USA, 1999, pp. 520-527.

[34] J. Cassell et al., "Animated Conversation: Rule-based Generation of Facial Expression, Gesture \& Spoken Intonation for Multiple Conversational Agents," in Proc. Annual Conf. Computer Graphics and Interactive Techniques, New York, NY, USA, 1994, pp. 413-420.

[35] F. Pecune, J. Chen, Y. Matsuyama, and J. Cassell, "Field Trial Analysis of Socially Aware Robot Assistant," in Proc. Intl. Conf. Autonomous Agents and MultiAgent Systems p. 9, 2018.

[36] T. Verhagen, J. van Nes, F. Feldberg, and W. van Dolen, "Virtual Customer Service Agents: Using Social Presence and Personalization to Shape Online Service Encounters," J Comput Mediat Commun, vol. 19, no. 3, pp. 529-545, Apr. 2014.

[37] G. Kress, Multimodality: A Social Semiotic Approach to Contemporary Communication. Abingdon; New York: Routledge, 2009. 